\title{
Association Among Calf Circumference, Physical Performance, and Depression in the Elderly Chinese Population: A Cross-Sectional Study
}

\section{Jian-Yu Tan}

The First Affiliated Hospital of Chongqing Medical University

\section{Qing-Lian Zeng}

The First Affiliated Hospital of Chongqing Medical University

\section{Meng Ni}

International Peace Maternity and Child Health Hospital, Shanghai Jiao Tong University

\section{Ying-Xiao Zhang}

The First Affiliated Hospital of Chongqing Medical University

\section{Tian Qiu ( $\nabla$ tianqiu131@sina.com )}

The First Affiliated Hospital of Chongqing Medical University

\section{Research Article}

Keywords: depression, sarcopenia, muscle mass, elderly, calf circumference, physical performance

Posted Date: December 29th, 2021

DOI: https://doi.org/10.21203/rs.3.rs-1163096/v1

License: (a) This work is licensed under a Creative Commons Attribution 4.0 International License. Read Full License

Version of Record: A version of this preprint was published at BMC Psychiatry on April 20th, 2022. See the published version at https://doi.org/10.1186/s12888-022-03925-z. 


\section{Abstract}

Background: Depression and sarcopenia are common diseases in the elderly population. However, the association between them is controversial. Based on the Chinese Longitudinal Healthy Longevity Survey (CLHLS) database, a cross-sectional study was conducted to explore the relationship between calf circumference, physical performance, and depression.

Methods: From the $8^{\text {th }}$ wave of CLHLS conducted in 2018, data on calf circumference, physical performance, depressive symptoms, and demographic, socioeconomic, and health-related characteristics were collected. A statistical analysis was conducted to explore the relationship between calf circumference, physical performance, and depressive symptoms. Confounding factors were adjusted for in the multiple logistic regression analysis.

Results: A total of 12,227 participants, including 5689 (46.5\%) men and 6538 (53.5\%) women (mean age, 83.4 years), were included in this study. After adjusting for confounding factors, the association between calf circumference and depression disappeared (odds ratio [OR] $=1.04,95 \%$ confidence interval [Cl]: $0.92-1.17, p=0.58)$. However, a significant inverse correlation persisted between physical performance and depressive symptoms $(\mathrm{OR}=1.16,95 \% \mathrm{Cl}: 1.13-1.20, p \rrbracket 0.001)$. The subgroup analysis revealed a significant association of calf circumference $(\mathrm{OR}=1.3,95 \% \mathrm{Cl}: 1.04-1.62, p=0.02)$ and physical performance $(\mathrm{OR}=1.15,95 \% \mathrm{Cl}: 1.08-1.22, p<0.001)$ with depression in the regular exercise group.

Conclusions: Physical performance was significantly associated with depression in the elderly Chinese population. Attention should be paid to assess depressive symptoms in patients with poor muscle condition.

\section{Background}

Depression, the most common type of mood disorder, is characterized by significant and persisting sadness [1]. According to a statistical analysis by the World Health Organization, depression is the leading cause of disability [2]. Depressive symptoms are common in later life, affecting approximately $10 \%$ of the elderly population [3].

Sarcopenia is characterized by age-related loss of skeletal muscle mass and function [4]. Its prevalence ranges from 5.5-25.7\% in Asian countries [4] and may be underestimated in the elderly population [5]. The pathophysiology of sarcopenia includes oxidative stress, chronic inflammation, hormonal deficiency, physical inactivity, and malnutrition [6], which may also be involved in the pathogenesis of depression [7-11].

Exercise can improve mood in patients with depression and strengthen muscles, thus improving physical performance. In a randomized controlled trial, exercise intervention using a physical activity program positively affected the depressive status. Moreover, muscles are the largest group of tissues involved in 
exercise and endocrine metabolism. Therefore, many studies have investigated the relationship between sarcopenia and depression [12-17].

However, none of the studies considered a large sample size of the elderly Chinese population. Therefore, the aim of the present study was to investigate the relationship between muscle condition and depression in the elderly Chinese population utilizing the Chinese Longitudinal Healthy Longevity Survey (CLHLS) database, a nationally representative sample.

\section{Methods}

\section{Study population}

Data from the $8^{\text {th }}$ wave of the CLHLS conducted in 2018/2019 were utilized. In CLHLS, the trained staff had collected data from the elderly Chinese population through face-to-face interviews. The information included demographic, socioeconomic, lifestyle-related, and health-related characteristics. Detailed information of the CLHLS has been previously reported $[18,19]$.

We collected information on calf circumference and physical performance from the 2018 wave of the CLHLS and assessed depressive symptoms based on the Center for Epidemiologic Studies Depression Scale (CES-D). After excluding 3,560 individuals with missing data on calf circumference and CES-D, 87 individuals aged below 65 years, a total of 12,227 participants were included in this study (Figure 1).

\section{Measurements}

The questionnaire in the 2018 wave of the CLHLS included calf circumference measured in $\mathrm{cm}$. According to previous studies and the Asian Working Group for Sarcopenia (AWGS) 2019 consensus [4], calf circumference was used as a measure of muscle mass. The muscle mass is considered low when the calf circumference $₫ 34 \mathrm{~cm}$ in men and $₫ 33 \mathrm{~cm}$ in women $[4,20-22]$.

The questionnaire in the 2018 wave of the CLHLS assessed physical performance on a four-item scale. Muscle strength was assessed using the question "Are you able to lift $5 \mathrm{~kg}$ of weight?" Walking ability was assessed using the question "Are you able to walk $1 \mathrm{~km}$ ?" The strength of the lower extremities was assessed using the question "Are you able to crouch and stand three times?" Finally, core strength was assessed using the question "How do you stand up after sitting in a chair?" The respondents were requested to choose from responses "without problem," "with problem," and "not able to," which were assigned scores of 0,1 , and 2 points, respectively. The total score ranged from 0 to 8 points. A higher score indicated low physical performance.

The 10-item CES-D-10 was used to assess depressive symptoms, as reported previously [23]. The options were "rarely," "some days," "occasionally," and "most of the time," which were assigned scores of 0, 1, 2, and 3 points, respectively. There were two positive questions: "Do you feel as happy as you did when you were young?" and "Are you full of hope for the future?" The results of these two questions were reversely 
coded before summation. The total score ranged from 0 to 30 points. A higher score indicated greater severity of depressive symptoms. A score $\geq 10$ in the CES-D-10 was considered to indicate depression, as validated by previous studies [24].

\section{Potential confounding factors}

The accuracy of results was improved by adjusting for confounding factors, including demographic characteristics (age and sex), socioeconomic characteristics (residence, education, marital status, and retirement status), lifestyle- and health-related behaviors (smoking status, drinking status, activities of daily living $[A D L])$, social and leisure activity index, travel in the past two years, regular dietary intake of vegetables/fruits/meat/fish/milk products/food made from beans/eggs/nuts, regular tea drinking, and exercise), and health status (body mass index [BMI], cognitive function, and medical history).

The educational level was dichotomized according to the number of years of schooling ( 0 and $\geq 1$ year). $A D L$ ability was assessed on an eight-item scale. ADL disability was defined as the need for an assistant to perform one or more of the five activities (bathing, dressing, toileting, indoor transferring, and feeding) or being incontinent. The social and leisure activity index was calculated using questions on gardening, tai chi chuan, square dancing, reading, raising animals/pets, playing mah-jongg/cards, watching television/listening to the radio, and participating in social activities. The options were "almost every day," "sometimes," and "never," which were assigned scores of 1, 2, and 3 points, respectively. The total score ranged from 8 to 24 points. A higher score indicated lack of social and leisurely activities.

The Chinese version of the 30-point Mini-Mental State Examination (MMSE) was used for cognitive function assessment. Cognitive impairment was defined as a total score < 24 on MMSE [25]. The questionnaire included 14 self-reported medical conditions. Chronic inflammatory disorder was defined as the presence of one or more of the following ten conditions: heart disease, stroke, diabetes, gastritis, pneumonia, cholecystitis, arthritis, rheumatism, nephritis, and hepatitis.

\section{Statistical analysis}

The data were statistically analyzed using the chi-square test, Student's $t$ test, or Mann-Whitney U test, as appropriate. Multiple logistic regression was used to calculate the odds ratio (OR) of depressive symptoms for muscle condition. To clarify the effects of muscle condition on depression, a stepwise approach was used to adjust for different sets of confounding factors. Model 1 included muscle mass and physical performance. Model 2 was adjusted for socioeconomic characteristics. Model 3 was additionally adjusted for lifestyle- and health-related behaviors. Model 4 was additionally adjusted for the health status.

Subgroup analyses were conducted to examine the association between muscle condition and depression by age, sex, cognitive function, exercise, ADL ability, and medical history. All subgroup analyses were performed on model 4. The data were analyzed using IBM SPSS Statistics version 20.0 for Windows (SPSS Inc., Chicago, IL). Two-tailed $p$-value $<0.05$ was considered statistical significance. 


\section{Results}

\section{General characteristics}

This study involved 12,227 participants (mean age: 83.4 years), including 4,904 aged 65-79 years and 7,323 aged $\geq 80$ years (Table 1). The mean CES-D-10 score was $7.4 \pm 4.5$ (95\% confidence interval [Cl]: 7.31-7.47). A CES-D-10 score $\geq 10$, indicating depression, was found in 3,335 (27.3\%) participants ( $95 \%$ Cl: $26.5 \%-28.1 \%)$. Low calf circumference was found in 7,680 (62.8\%) participants (95\% Cl: $61.9 \%-$ $63.7 \%)$, including 3192 (41.6\%) men and 4,488 (58.4\%) women. Low calf circumference was significantly associated with older age, separated or never-married marital status, regular alcohol consumption, rural residence, and retirement without pension. Further, it was associated with lesser participation in social and leisurely activities, ADL disability, relatively unhealthy diet, relatively less physical activity, depressive symptoms, chronic inflammatory disorders, and poor physical performance and cognitive function.

\section{Association between muscle condition and depressive symptoms}

Table 2 shows the results of the multiple logistic regression. In model 1 , muscle mass $(\mathrm{OR}=1.16,95 \% \mathrm{Cl}$ : $1.06-1.26, p=0.001)$ and physical performance $(\mathrm{OR}=1.18,95 \% \mathrm{Cl}: 1.16-1.20, p<0.001)$ were significantly associated with depressive symptoms, supporting the hypothesis that poor muscle condition increases the likelihood of depression in the elderly population. In model 2, which was adjusted for demographic characteristics, the impact of muscle mass attenuated $(\mathrm{OR}=1.12,95 \% \mathrm{Cl}: 1.01-1.24, p=$ $0.03)$, while that of physical performance strengthened ( $\mathrm{OR}=1.22,95 \% \mathrm{Cl}: 1.20-1.25, p<0.001)$. In models 3 and 4, which were adjusted for lifestyle- and health-related behaviors and health status, only the association between physical performance and depressive symptoms persisted $(\mathrm{OR}=1.16,95 \% \mathrm{Cl}$ : $1.13-$ $1.20, p<0.001)$.

After adjusting for confounding factors, depressive symptoms were associated with younger age, lesser educational level, separated or never-married marital status, less participation in social and leisurely activities, lesser frequency of travel, lower intake of fruits, vegetables, and eggs, lesser exercise, and presence of chronic inflammatory disorders. In the subgroup analysis (Table 3), the association between physical performance and depressive symptoms was consistent and more pronounced in the young-old population (65-80 years), men, participants not exercising regularly, and participants with cognitive impairment or chronic inflammatory disorders. In the regular exercise group, the association between muscle mass $(\mathrm{OR}=1.3 ; 95 \% \mathrm{Cl}: 1.04-1.61 ; p<0.05)$, physical performance $(\mathrm{OR}=1.15,95 \% \mathrm{Cl}: 1.08-$ $1.22, p<0.001)$, and depressive symptoms was significant.

\section{Discussion}

Utilizing a nationally representative large-scale survey of the elderly (aged $\geq 65$ years) Chinese population, a cross-sectional study was conducted to investigate the relationship between muscle condition and depression. The association between physical performance and depression was found to be pronounced, consistent with previous studies(26-29). Physical inactivity was a common risk factor for 
sarcopenia and depression and could mediate the relationship between them(31). Furthermore, muscle condition and depression share common pathogenesis(32). Contracting skeletal muscles secrete neurotrophic factors, which play a role in mood. Neurotrophins, such as brain-derived neurotrophic factor and neurotrophin-3, which promote neuronal differentiation, survival, and synaptic potentiation, are produced by both the brain and skeletal muscle and are associated with mood and muscle regeneration(33). This may be the potential mechanism underlying the association between sarcopenia and mental illness, as decreased neurotrophic support of the brain is associated with depression and anxiety(34). Chronic low-grade inflammation and oxidative stress, which are associated with both depression and sarcopenia, may be another possible mechanism $(7,35)$. The relationship between sarcopenia and depression may result from physical activity and brain plasticity and inflammation. Potential intervention of these factors might not only relieve depression but also improve sarcopenia.

In this study, people with larger calf circumferences were less likely to have depressive symptoms. Further, after adjusting for potential confounding factors, the impact of calf circumference attenuated, consistent with previous studies $(27,36)$. However, unlike previous studies, the regular exercise group showed an inverse association between muscle mass and depression. A European consensus indicates that age-related changes in fat deposits and loss of skin elasticity can lead to estimation errors of the calf circumference in the elderly population(37). Therefore, calf circumference may not be a good predictor of muscle mass in that population. In the regular exercise group, age-related changes may have been attenuated. Thus, the association between calf circumference and depression became significant. Furthermore, in the group that did not exercise regularly, individuals may have developed sarcopenic obesity, which can result in a reduced predictive value of the calf circumference for muscle mass.

Some similar previous studies have been conducted in ethnic groups other than the Chinese. An English study showed that reduction in grip strength is associated with a higher risk of depressive symptoms in participants with obesity(38). A Japanese cross-sectional study found a significant association between sarcopenia and depression in elderly male patients with diabetes, measured by "Strength, assistance with walking, rising from a chair, climbing stairs, and falls" (SARC-F) and CES-D questionnaires(39). A Korean study found that the coexistence of low muscle mass and low muscle function is significantly associated with an increased risk of depressive symptoms(40). Because of the complexity of sarcopenia diagnosis, many studies have shown a correlation with one component of its diagnostic criteria, insufficient to prove a link between muscle condition (muscle mass, muscle strength, or physical performance) and depression. More prospective and large-scale studies are required to clarify the relationship between muscle condition and depression.

The advantage of our study was the use of a large sample size of the elderly Chinese population. To obtain robust results, we adjusted for many confounding factors. However, the study has some limitations should be acknowledged. Firstly, we selected four questions in the questionnaire to evaluate participants' physical performance by reference to SARC-F, which was recommended to screening sarcopenia by AWGS 2019 Consensus(3). However, the evaluation efficiency of the questionnaire composed of these four questions has not been tested. So the results of the present study may lack 
universality. Second, due to the cross-sectional study design, the causal relationship between muscle condition and depression could not be clarified. Prospective studies are required to address this limitation.

\section{Conclusions}

Depression and sarcopenia are common diseases in the elderly population. This study showed a strong association between physical performance and depression. Future studies should focus on comorbidities of depression and sarcopenia in the elderly population and the effect of regular exercise on depressive mood.

\section{Abbreviations}

CLHLS: Chinese Longitudinal Healthy Longevity Survey; OR: Odds ratio; Cl: Confidence interval; CES-D: Center for Epidemiologic Studies Depression Scale; AWGS: Asian Working Group for Sarcopenia; ADL: Activities of daily living; BMI: Body mass index; MMSE: Mini-Mental State Examination;

\section{Declarations}

Ethics approval and consent to participate: This study was carried out in accordance with the Declaration of Helsinki as revised 1989. The 2018 wave of CLHLS study was approved by the Biomedical Ethics Committee of Peking University (IRB00001052-13074). All participants or their legal representatives signed written consent forms in the baseline and follow-up surveys.

Consent for publication: Not applicable

Availability of data and materials: The data that support the findings of this study are available in https://opendata.pku.edu.cn/dataverse/CHADS [41].

Competing interests: Not applicable

Funding: Not applicable

Authors' contributions: JYT and TQ designed the research. JYT, TQ and MN wrote the manuscript and analyzed the data. JYT, QLZ, MN and YXZ contributed to the data collection. All authors have read and approved the manuscript.

Acknowledgements: The authors acknowledge the efforts of this research team and appreciate all the participants for attending this research.

\section{References}


1. Chand SP, Arif H. Depression. StatPearls. Treasure Island (FL): StatPearls Publishing Copyright $(\odot$ 2021, StatPearls Publishing LLC.; 2021.

2. Global, regional, and national incidence, prevalence, and years lived with disability for 354 diseases and injuries for 195 countries and territories, 1990-2017: a systematic analysis for the Global Burden of Disease Study 2017. Lancet. 2018;392(10159):1789-858.

3. Beekman AT, Copeland JR, Prince MJ. Review of community prevalence of depression in later life. The British journal of psychiatry : the journal of mental science. 1999;174:307-11.

4. Chen LK, Woo J, Assantachai P, Auyeung TW, Chou MY, lijima K, et al. Asian Working Group for Sarcopenia: 2019 Consensus Update on Sarcopenia Diagnosis and Treatment. Journal of the American Medical Directors Association. 2020;21(3):300-7.e2.

5. Cohen S, Nathan JA, Goldberg AL. Muscle wasting in disease: molecular mechanisms and promising therapies. (1474-1784 (Electronic)).

6. Budui SL, Rossi AP, Zamboni M. The pathogenetic bases of sarcopenia. (1724-8914 (Print)).

7. Sepehrmanesh Z, Kolahdooz F, Abedi F, Mazroii N, Assarian A, Asemi Z, et al. Vitamin D Supplementation Affects the Beck Depression Inventory, Insulin Resistance, and Biomarkers of Oxidative Stress in Patients with Major Depressive Disorder: A Randomized, Controlled Clinical Trial. The Journal of nutrition. 2016;146(2):243-8.

8. Berk M, Williams LJ, Jacka FN, O'Neil A, Pasco JA, Moylan S, et al. So depression is an inflammatory disease, but where does the inflammation come from? BMC Med. 2013;11:200.

9. Velázquez-Alva MC, Irigoyen-Camacho ME, Cabrer-Rosales MF, Lazarevich I, Arrieta-Cruz I, GutiérrezJuárez R, et al. Prevalence of Malnutrition and Depression in Older Adults Living in Nursing Homes in Mexico City. Nutrients. 2020;12(8).

10. Vancampfort D, Firth J, Schuch FB, Rosenbaum S, Mugisha J, Hallgren M, et al. Sedentary behavior and physical activity levels in people with schizophrenia, bipolar disorder and major depressive disorder: a global systematic review and meta-analysis. World psychiatry : official journal of the World Psychiatric Association (WPA). 2017;16(3):308-15.

11. Islam MZ, Disu TR, Farjana S, Rahman MM. Malnutrition and other risk factors of geriatric depression: a community-based comparative cross-sectional study in older adults in rural Bangladesh. BMC geriatrics. 2021;21(1):572.

12. Dunn AL, Trivedi Mh Fau - Kampert JB, Kampert Jb Fau - Clark CG, Clark Cg Fau - Chambliss HO, Chambliss HO. Exercise treatment for depression: efficacy and dose response. (0749-3797 (Print)).

13. Kokkeler KA-O, van den Berg KS, Comijs HC, Oude Voshaar RC, Marijnissen RM. Sarcopenic obesity predicts nonremission of late-life depression. (1099-1166 (Electronic)).

14. Kim NH, Kim Hs Fau - Eun CR, Eun Cr Fau - Seo JA, Seo Ja Fau - Cho HJ, Cho Hj Fau - Kim SG, Kim $\mathrm{Sg}$ Fau - Choi KM, et al. Depression is associated with sarcopenia, not central obesity, in elderly korean men. (1532-5415 (Electronic)).

15. Cho Y, Shin SY, Shin MJ. Sarcopenic obesity is associated with lower indicators of psychological health and quality of life in Koreans. (1879-0739 (Electronic)). 
16. Hamer M, Batty GD, Kivimaki M. Sarcopenic obesity and risk of new onset depressive symptoms in older adults: English Longitudinal Study of Ageing. (1476-5497 (Electronic)).

17. Fukumori N, Yamamoto Y, Takegami M, Yamazaki S, Onishi Y, Sekiguchi M, et al. Association between hand-grip strength and depressive symptoms: Locomotive Syndrome and Health Outcomes in Aizu Cohort Study (LOHAS). (1468-2834 (Electronic)).

18. Zeng Y, Feng Q, Gu D, Vaupel JW. Demographics, phenotypic health characteristics and genetic analysis of centenarians in China. Mechanisms of ageing and development. 2017;165(Pt B):86-97.

19. Zeng Y, Feng Q, Hesketh T, Christensen K, Vaupel JW. Survival, disabilities in activities of daily living, and physical and cognitive functioning among the oldest-old in China: a cohort study. (1474-547X (Electronic)).

20. Kawakami R, Miyachi M, Sawada SS, Torii S, Midorikawa T, Tanisawa K, et al. Cut-offs for calf circumference as a screening tool for low muscle mass: WASEDA'S Health Study. Geriatrics \& gerontology international. 2020;20(10):943-50.

21. Gonzalez MC, Mehrnezhad A, Razaviarab N, Barbosa-Silva TG, Heymsfield SB. Calf circumference: cutoff values from the NHANES 1999-2006. Am J Clin Nutr. 2021;113(6):1679-1687.

22. Chen CY, Tseng WC, Yang YH, Chen CL, Lin LL, Chen FP, et al. Calf Circumference as an Optimal Choice of Four Screening Tools for Sarcopenia Among Ethnic Chinese Older Adults in Assisted Living. Clin Interv Aging. 2020;15:2415-2422.

23. Andresen EM, Malmgren JA, Carter WB, Patrick DL. Screening for depression in well older adults: evaluation of a short form of the CES-D (Center for Epidemiologic Studies Depression Scale). American journal of preventive medicine. 1994;10(2):77-84.

24. Liu Y, Chen X, Yan Z. Depression in the house: The effects of household air pollution from solid fuel use among the middle-aged and older population in China. The Science of the total environment. 2020;703:134706.

25. Zeng Y, Feng Q, Hesketh T, Christensen K, Vaupel JW. Survival, disabilities in activities of daily living, and physical and cognitive functioning among the oldest-old in China: a cohort study. Lancet. 2017;389(10079):1619-29.

26. Szlejf C, Suemoto CK, Brunoni AR, Viana MC, Moreno AB, Matos SMA, et al. Depression is Associated With Sarcopenia Due to Low Muscle Strength: Results From the ELSA-Brasil Study. Journal of the American Medical Directors Association. 2019;20(12):1641-6.

27. Hayashi T, Umegaki H, Makino T, Cheng XW, Shimada H, Kuzuya M. Association between sarcopenia and depressive mood in urban-dwelling older adults: A cross-sectional study. Geriatrics \& gerontology international. 2019;19(6):508-12.

28. Everson-Rose SA, Skarupski KA, Bienias JL, Wilson RS, Evans DA, Mendes de Leon CF. Do depressive symptoms predict declines in physical performance in an elderly, biracial population? Psychosomatic medicine. 2005;67(4):609-15.

29. Hamer M, Batty GD, Kivimaki M. Sarcopenic obesity and risk of new onset depressive symptoms in older adults: English Longitudinal Study of Ageing. International journal of obesity (2005). 
2015;39(12):1717-20.

30. von Berens Å, Fielding RA, Gustafsson T, Kirn D, Laussen J, Nydahl M, et al. Effect of exercise and nutritional supplementation on health-related quality of life and mood in older adults: the VIVE2 randomized controlled trial. BMC geriatrics. 2018;18(1):286.

31. Hallgren M, Herring MP, Owen N, Dunstan D, Ekblom Ö, Helgadottir B, et al. Exercise, Physical Activity, and Sedentary Behavior in the Treatment of Depression: Broadening the Scientific Perspectives and Clinical Opportunities. Frontiers in psychiatry. 2016;7:36.

32. Delezie J, Handschin C. Endocrine Crosstalk Between Skeletal Muscle and the Brain. Frontiers in neurology. 2018;9:698.

33. Pasco JA, Williams LJ, Jacka FN, Stupka N, Brennan-Olsen SL, Holloway KL, et al. Sarcopenia and the Common Mental Disorders: a Potential Regulatory Role of Skeletal Muscle on Brain Function? Current osteoporosis reports. 2015;13(5):351-7.

34. Molendijk ML, Bus BA, Spinhoven P, Penninx BW, Prickaerts J, Oude Voshaar RC, et al. Gender specific associations of serum levels of brain-derived neurotrophic factor in anxiety. The world journal of biological psychiatry : the official journal of the World Federation of Societies of Biological Psychiatry. 2012;13(7):535-43.

35. Schaap LA, Pluijm SM, Deeg DJ, Harris TB, Kritchevsky SB, Newman AB, et al. Higher inflammatory marker levels in older persons: associations with 5-year change in muscle mass and muscle strength. The journals of gerontology Series A, Biological sciences and medical sciences. 2009;64(11):1183-9.

36. Chen L, Sheng Y, Qi H, Tang T, Yu J, Lv S. Correlation of sarcopenia and depressive mood in older community dwellers: a cross-sectional observational study in China. BMJ open. 2020;10(9):e038089.

37. Cruz-Jentoft AJ, Bahat G, Bauer J, Boirie Y, Bruyère O, Cederholm T, et al. Sarcopenia: revised European consensus on definition and diagnosis. Age and ageing. 2019;48(4):601.

38. Hamer M, Batty GD, Kivimaki M. Sarcopenic obesity and risk of new onset depressive symptoms in older adults: English Longitudinal Study of Ageing. Int J Obes (Lond). 2015;39(12):1717-20.

39. Ida SA-O, Murata K, Nakai M, Ito S, Malmstrom TK, Ishihara Y, et al. Relationship between sarcopenia and depression in older patients with diabetes: An investigation using the Japanese version of SARCF. (1447-0594 (Electronic)).

40. Jin YA-O, Kang S, Kang HA-O. Individual and Synergistic Relationships of Low Muscle Mass and Low Muscle Function with Depressive Symptoms in Korean Older Adults. LID - 10.3390/ijerph181910129 [doi] LID - 10129. (1660-4601 (Electronic)).

41. The Chinese Longitudinal Healthy Longevity Survey (CLHLS)-Longitudinal Data囚1998-2018囚. V2ed: Peking University Open Research Data Platform; 2020. https://opendata.pku.edu.cn/ dataverse/CHADS.

\section{Tables}


Table 1. Characteristics of the entire study population and subgroups based on the type of muscle mass 


\begin{tabular}{|c|c|c|c|c|}
\hline Variables/Subgroups & $\begin{array}{l}\text { Total } \\
\text { sample }\end{array}$ & $\begin{array}{l}\text { Low muscle } \\
\text { mass }\end{array}$ & $\begin{array}{l}\text { Normal muscle } \\
\text { mass }\end{array}$ & $\begin{array}{l}p- \\
\text { value }\end{array}$ \\
\hline Total sample & 12,227 & $7,680(62.8 \%)$ & $4,547(37.2 \%)$ & \\
\hline Age (years) & $83.4 \pm 11.0$ & $85.9 \pm 10.9$ & $79.1 \pm 9.8$ & $\varangle 0.001$ \\
\hline Female & $\begin{array}{l}6,538 \\
(53.5 \%)\end{array}$ & $4,488(58.4 \%)$ & $2,050(45.1 \%)$ & $\varangle 0.001$ \\
\hline Rural residence & $\begin{array}{l}5,327 \\
(43.6 \%)\end{array}$ & $3,584(46.7 \%)$ & $1,743(38.3 \%)$ & $\nabla 0.001$ \\
\hline Educated & $\begin{array}{l}5,857 \\
(55.8 \% \rrbracket\end{array}$ & $3,096(47.3 \%)$ & $2,761(69.8 \%)$ & $\nabla 0.001$ \\
\hline Living with a spouse & $\begin{array}{l}5,417 \\
(44.3 \%)\end{array}$ & $2,832(37.3 \%)$ & $2,585(57.3 \%)$ & $\nabla 0.001$ \\
\hline Retired with pension & $\begin{array}{l}3,452 \\
(28.2 \%)\end{array}$ & $1,669(22.5 \%)$ & $1,783(40.4 \%)$ & $\varangle 0.001$ \\
\hline Current smoker & $\begin{array}{l}1,964 \\
(16.1 \%)\end{array}$ & $1,199(15.9 \%)$ & $765(17.1 \%)$ & 0.089 \\
\hline Current alcohol drinker & $\begin{array}{l}1,856 \\
(15.2 \%)\end{array}$ & $1,042(13.9 \%)$ & $814(18.3 \%)$ & $\bowtie 0.001$ \\
\hline ADL disability & $\begin{array}{l}2,226 \\
(18.2 \%)\end{array}$ & $1,645(22 \%)$ & $581(13.3 \%)$ & $\nabla 0.001$ \\
\hline Social and leisure activity index & $20.9 \pm 2.4$ & $21.4 \pm 2.2$ & $20.2 \pm 2.5$ & $\triangle 0.001$ \\
\hline Have traveled in the past 2 years & $\begin{array}{l}1,659 \\
(13.6 \%)\end{array}$ & $727(9.6 \%)$ & $932(20.7 \%)$ & $\varangle 0.001$ \\
\hline \multicolumn{5}{|l|}{ Regular intake of } \\
\hline Vegetables & $\begin{array}{l}8,045 \\
(65.8 \%)\end{array}$ & $4,874(63.6 \%)$ & $3,171(69.9 \%)$ & $\nabla 0.001$ \\
\hline Fruits & $\begin{array}{l}2,765 \\
(22.6 \%)\end{array}$ & $1,478(19.3 \%)$ & $1,287(28.4 \%)$ & $\otimes 0.001$ \\
\hline Meat & $\begin{array}{l}4,999 \\
(41.3 \%)\end{array}$ & $3,114(41.1 \%)$ & $1,885(41.8 \%)$ & 0.441 \\
\hline Fish & $1,156(9.5 \%)$ & $643(8.5 \%)$ & $513(11.4 \%)$ & $\otimes 0.001$ \\
\hline Milk products & $\begin{array}{l}2,886 \\
(23.9 \%)\end{array}$ & $1,610(21.3 \%)$ & $1,276(28.3 \%)$ & $\triangle 0.001$ \\
\hline Food made from beans & $\begin{array}{l}1,506 \\
(12.5 \%)\end{array}$ & $865(11.4 \%)$ & $641(14.2 \%)$ & $\nabla 0.001$ \\
\hline Eggs & $\begin{array}{l}4,663 \\
(38.6 \%)\end{array}$ & $2,721(35.9 \%)$ & $1,942(43.1 \%)$ & $\nabla 0.001$ \\
\hline
\end{tabular}




\begin{tabular}{|c|c|c|c|c|}
\hline Nuts & $810(6.6 \%)$ & $379(5 \%)$ & $431(9.6 \%)$ & $\varangle 0.001$ \\
\hline Tea & $\begin{array}{l}2,185 \\
(17.9 \%)\end{array}$ & $1,122(15 \%)$ & $1,063(23.8 \%)$ & $\bowtie 0.001$ \\
\hline Regular exercise & $\begin{array}{l}4,174 \\
(34.1 \%)\end{array}$ & $2,214(29.2 \%)$ & $1,960(43.7 \%)$ & $\nabla 0.001$ \\
\hline \multicolumn{5}{|l|}{ CES-D-10 } \\
\hline Total score (points) & $7.4 \pm 4.5$ & $7.7 \pm 4.4$ & $6.9 \pm 4.5$ & $\varangle 0.001$ \\
\hline Total score $\geq 10$ & $\begin{array}{l}3,335 \\
(27.3 \%)\end{array}$ & $2,274(29.6 \%)$ & $1,061(23.3 \%)$ & $\varangle 0.001$ \\
\hline $\mathrm{BMI}\left(\mathrm{kg} / \mathrm{m}^{2}\right)$ & $22.4 \pm 8.0$ & $21.1 \pm 8.4$ & $24.7 \pm 6.7$ & $\varangle 0.001$ \\
\hline $\begin{array}{l}\text { Physical performance index } \\
\text { (points) }\end{array}$ & $1(0,4)$ & $2(0,5)$ & $0(0,3)$ & $\varangle 0.001$ \\
\hline Cognitive impairment & $\begin{array}{l}2,050 \\
(16.8 \%)\end{array}$ & $1,605(25.2 \%)$ & $445(11 \%)$ & $\varangle 0.001$ \\
\hline Chronic inflammatory disorders & $\begin{array}{l}5,540 \\
(45.3 \%)\end{array}$ & $3,217(41.9 \%)$ & $2,323(51.1 \%)$ & $\varangle 0.001$ \\
\hline
\end{tabular}

Data are expressed as number (frequency) unless otherwise specified. Abbreviations: ADL: activities of daily living; CES-D-10: 10-item Center for Epidemiological Studies; BMI: body mass index

Table 2. Multiple logistic regression analysis of the association between muscle condition and depression 


\begin{tabular}{|c|c|c|c|c|c|c|c|c|}
\hline & \multicolumn{2}{|c|}{ Model 1} & \multicolumn{2}{|c|}{ Model 2} & \multicolumn{2}{|c|}{ Model 3} & \multicolumn{2}{|c|}{ Model 4} \\
\hline & OR & $95 \% \mathrm{Cl}$ & OR & $\begin{array}{l}95 \% \\
\mathrm{Cl}\end{array}$ & OR & $\begin{array}{l}95 \% \\
\mathrm{Cl}\end{array}$ & OR & $\begin{array}{l}95 \% \\
\mathrm{Cl}\end{array}$ \\
\hline Low muscle mass & $1.16^{* \star}$ & $\begin{array}{l}1.06- \\
1.26\end{array}$ & $1.12^{\star \star}$ & $\begin{array}{l}1.01- \\
1.24\end{array}$ & 1.05 & $\begin{array}{l}0.94- \\
1.18\end{array}$ & 1.04 & $\begin{array}{l}0.92- \\
1.17\end{array}$ \\
\hline Physical performance & $1.18^{\star \star \star}$ & $\begin{array}{l}1.16- \\
1.20\end{array}$ & $1.22^{\star \star \star}$ & $\begin{array}{l}1.20- \\
1.25\end{array}$ & $1.19^{\star \star \star}$ & $\begin{array}{l}1.15- \\
1.22\end{array}$ & $1.16^{\star \star \star}$ & $\begin{array}{l}1.13- \\
1.20\end{array}$ \\
\hline Age & & & $0.97^{\star \star \star}$ & $\begin{array}{l}0.97- \\
0.98\end{array}$ & $0.97^{\star \star \star}$ & $\begin{array}{l}0.96- \\
0.98\end{array}$ & $0.97^{\star \star \star}$ & $\begin{array}{l}0.97- \\
0.98\end{array}$ \\
\hline Female & & & 1.08 & $\begin{array}{l}0.98- \\
1.20\end{array}$ & 1.06 & $\begin{array}{l}0.93- \\
1.18\end{array}$ & 1.01 & $\begin{array}{l}0.88- \\
1.15\end{array}$ \\
\hline Rural residence & & & 0.98 & $\begin{array}{l}0.89- \\
1.09\end{array}$ & 0.98 & $\begin{array}{l}0.82- \\
1.02\end{array}$ & 0.95 & $\begin{array}{l}0.84- \\
1.07\end{array}$ \\
\hline Educated & & & $0.75^{\star \star \star}$ & $\begin{array}{l}0.67- \\
0.84\end{array}$ & $0.85^{\star \star}$ & $\begin{array}{l}0.75- \\
0.96\end{array}$ & $0.84^{\star *}$ & $\begin{array}{l}0.74- \\
0.97\end{array}$ \\
\hline Living with a spouse & & & $1.23^{\star \star \star}$ & $\begin{array}{l}1.10- \\
1.38\end{array}$ & $1.21^{\star \star}$ & $\begin{array}{l}1.07- \\
1.36\end{array}$ & $1.19^{\star \star}$ & $\begin{array}{l}1.04- \\
1.36\end{array}$ \\
\hline Retired with pension & & & $1.22^{\star \star \star}$ & $\begin{array}{l}1.10- \\
1.40\end{array}$ & 0.91 & $\begin{array}{l}0.78- \\
1.03\end{array}$ & 1.02 & $\begin{array}{l}0.85- \\
1.15\end{array}$ \\
\hline Current smoker & & & & & 1.00 & $\begin{array}{l}0.85- \\
1.16\end{array}$ & 1.03 & $\begin{array}{l}0.87- \\
1.21\end{array}$ \\
\hline Current alcohol drinker & & & & & $0.83^{\star \star}$ & $\begin{array}{l}0.71- \\
0.97\end{array}$ & $0.86^{*}$ & $\begin{array}{l}0.72- \\
1.02\end{array}$ \\
\hline ADL disability & & & & & 0.98 & $\begin{array}{l}0.84- \\
1.13\end{array}$ & 1.16 & $\begin{array}{l}0.97- \\
1.37\end{array}$ \\
\hline $\begin{array}{l}\text { Social and leisure } \\
\text { activity index }\end{array}$ & & & & & $1.06^{\star \star \star}$ & $\begin{array}{l}1.03- \\
1.09\end{array}$ & $1.06^{\star \star \star}$ & $\begin{array}{l}1.02- \\
1.09\end{array}$ \\
\hline $\begin{array}{l}\text { Have traveled in the } \\
\text { past } 2 \text { years }\end{array}$ & & & & & $0.78^{\star \star}$ & $\begin{array}{l}0.66- \\
0.94\end{array}$ & $0.79^{\star \star}$ & $\begin{array}{l}0.67- \\
0.96\end{array}$ \\
\hline \multicolumn{9}{|l|}{ Regular intake of } \\
\hline Vegetables & & & & & $1.43^{* \star *}$ & $\begin{array}{l}1.29- \\
1.60\end{array}$ & $1.49^{\star \star \star}$ & $\begin{array}{l}1.32- \\
1.68\end{array}$ \\
\hline Fruits & & & & & $1.41^{\star \star \star}$ & $\begin{array}{l}1.22- \\
1.63\end{array}$ & $1.31^{\star \star}$ & $\begin{array}{l}1.11- \\
1.52\end{array}$ \\
\hline Meat & & & & & 1.07 & $\begin{array}{l}0.96- \\
1.17\end{array}$ & 1.07 & $\begin{array}{l}0.95- \\
1.21\end{array}$ \\
\hline Fish & & & & & $0.80^{\star \star}$ & $\begin{array}{l}0.67- \\
0.96\end{array}$ & $0.81^{\star \star}$ & $\begin{array}{l}0.68- \\
1.00\end{array}$ \\
\hline
\end{tabular}




\begin{tabular}{|c|c|c|c|c|}
\hline Milk products & 1.02 & $\begin{array}{l}0.89- \\
1.16\end{array}$ & 1.01 & $\begin{array}{l}0.86- \\
1.16\end{array}$ \\
\hline $\begin{array}{l}\text { Food made from } \\
\text { beans }\end{array}$ & 1.09 & $\begin{array}{l}0.93- \\
1.29\end{array}$ & 1.10 & $\begin{array}{l}0.91- \\
1.31\end{array}$ \\
\hline Eggs & $1.50^{\star \star \star}$ & $\begin{array}{l}1.34- \\
1.68\end{array}$ & $1.51^{\star \star \star}$ & $\begin{array}{l}1.31- \\
1.70\end{array}$ \\
\hline Nuts & 1.14 & $\begin{array}{l}0.90- \\
1.43\end{array}$ & 1.13 & $\begin{array}{l}0.88- \\
1.44\end{array}$ \\
\hline Tea & 1.13 & $\begin{array}{l}0.97- \\
1.30\end{array}$ & 1.14 & $\begin{array}{l}0.97- \\
1.32\end{array}$ \\
\hline Regular exercise & $1.41^{\star \star \star}$ & $\begin{array}{l}1.25- \\
1.59\end{array}$ & $1.49^{* \star *}$ & $\begin{array}{l}1.31- \\
1.69\end{array}$ \\
\hline BMI & & & 1.00 & $\begin{array}{l}1.00- \\
1.01\end{array}$ \\
\hline Cognitive impairment & & & $0.75^{\star \star \star}$ & $\begin{array}{l}0.65- \\
0.87\end{array}$ \\
\hline $\begin{array}{l}\text { Chronic inflammatory } \\
\text { disorders }\end{array}$ & & & $0.58^{\star \star \star}$ & $\begin{array}{l}0.52- \\
0.65\end{array}$ \\
\hline
\end{tabular}

${ }^{*} p \otimes 0.01 ;{ }^{* *} p \otimes 0.05 ;{ }^{* \star} p \otimes 0.001$

Abbreviations: OR: odds ratio; Cl: confidence interval; ADL: activities of daily living; BMI: body mass index; Model 1 included muscle mass and physical performance.

Model 2 was adjusted for socioeconomic characteristics, including residence, education, marital status, and retirement status.

Model 3 was additionally adjusted for lifestyle- and health-related behaviors (smoking, alcohol consumption, activities for daily living ability, social and leisure activity index, travel, regular dietary intake, tea drinking, and exercise).

Model 4 was additionally adjusted for the health status, including the body mass index, cognitive function, and medical history.

Table 3. Subgroup analysis of the association between muscle condition and depression 


\begin{tabular}{|c|c|c|c|c|}
\hline \multirow[b]{2}{*}{ By age } & \multicolumn{2}{|c|}{ Muscle mass } & \multicolumn{2}{|c|}{ Physical performance } \\
\hline & OR & $95 \% \mathrm{Cl}$ & OR & $95 \% \mathrm{Cl}$ \\
\hline$<80$ & 1.16 & $0.97-1.38$ & $1.21^{\star \star \star}$ & $1.14-1.28$ \\
\hline$\geq 80$ & 0.93 & $0.79-1.11$ & $1.15^{\star \star \star}$ & $1.11-1.19$ \\
\hline \multicolumn{5}{|l|}{ By sex } \\
\hline Male & 1.01 & $0.84-1.22$ & $1.21^{\star \star \star}$ & $1.15-1.27$ \\
\hline Female & 1.05 & $0.88-1.24$ & $1.14^{\star \star \star}$ & $1.09-1.18$ \\
\hline \multicolumn{5}{|c|}{ By cognitive function } \\
\hline Impaired & 0.83 & $0.62-1.11$ & $1.17^{\star \star \star}$ & $1.10-1.24$ \\
\hline Not impaired & 1.08 & $0.95-1.24$ & $1.16^{\star \star \star}$ & $1.12-1.21$ \\
\hline \multicolumn{5}{|c|}{ Physical activity } \\
\hline Regular & $1.30^{\star \star}$ & $1.04-1.62$ & $1.15^{\star \star \star}$ & $1.08-1.22$ \\
\hline Not regular & 0.94 & $0.81-1.09$ & $1.17^{\star \star \star}$ & $1.13-1.21$ \\
\hline \multicolumn{5}{|l|}{ ADL disability } \\
\hline Yes & 0.98 & $0.72-1.33$ & $1.15^{\star \star \star}$ & $1.07-1.24$ \\
\hline No & 1.04 & $0.91-1.19$ & $1.17^{\star \star \star}$ & $1.13-1.21$ \\
\hline \multicolumn{5}{|c|}{ Chronic inflammatory disorders } \\
\hline Yes & 1.09 & $0.92-1.29$ & $1.17^{\star \star \star}$ & $1.12-1.22$ \\
\hline No & 0.99 & $0.82-1.19$ & $1.16^{\star \star \star}$ & $1.11-1.21$ \\
\hline
\end{tabular}

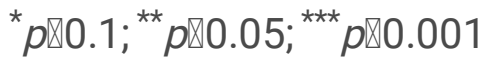

Abbreviations: OR: odds ratio; $\mathrm{Cl}$ : confidence interval; $\mathrm{ADL}$ : activities of daily living

Subgroup analyses were performed on model 4.

\section{Figures}




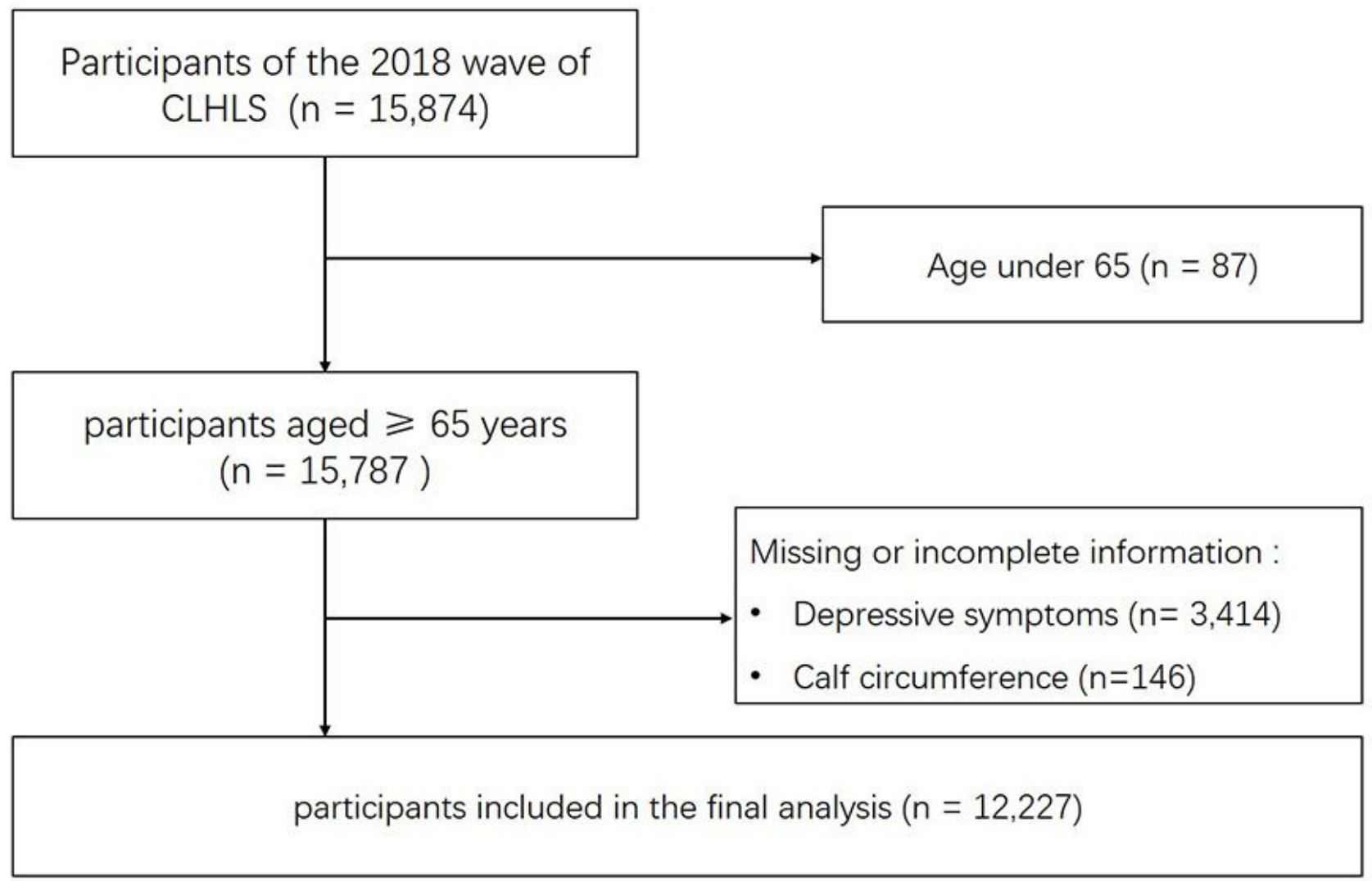

Figure 1

Flowchart of the selection of study population from participants of the Chinese Longitudinal Healthy Longevity Survey 